\title{
Iniciação Científica na segunda metade \\ dos anos finais do Ensino Fundamental: percursos da Equipe de Professores \\ do Projeto PIXEL do Colégio de Aplicação da UFRGS
}

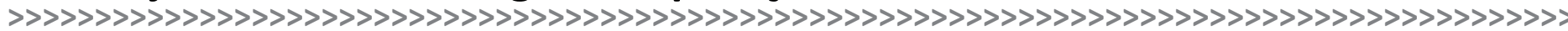

Vivian Ignes Albertoni et al.*

\section{Resumo:}

Este relato de experiência tem como objetivo apresentar como foi constituído e como estrutura-se atualmente o componente curricular Iniciação Científica (IC) no Projeto PIXEL, que abrange a segunda metade dos anos finais do Ensino Fundamental no Colégio de Aplicação (CAp) da UFRGS. O trabalho na IC organiza-se a partir de um planejamento semanal da equipe de professores, o que possibilitou uma série de reflexões e práticas neste componente curricular. O trabalho com a IC oportuniza o desenvolvimento de competências gerais em ambos os anos $\left(8^{\circ}\right.$ e $\left.9^{\circ}\right)$ de seu desenvolvimento. São elas: a argumentação, a autonomia, a autoria, a cooperação e a colaboração e a resolução de problemas. Essas competências são essenciais à IC e servem de referência para criar os critérios de avaliação, não somente desse componente curricular, mas de todos os demais componentes do Projeto de Ensino PIXEL. A IC ocorre em quatro períodos semanais e seus projetos são desenvolvidos ao longo de um semestre. Eles culminam em produções escritas estruturadas - em formatos de reportagem científica para os 8ㅇs anos, e com formatos diversos, que incluem desde relatórios até manuais para os $90^{\circ}$. Ambos os anos se envolvem em Mostras de Trabalhos, nas quais os estudantes apresentam seus processos de pesquisa utilizando-se dos mais diversos recursos, fazendo a devolutiva da investigação para a comunidade. O trabalho da IC na escola não se trata, portanto, de uma aula que propõe situações-problema hipotéticas na expectativa de que os estudantes encontrem a resposta "correta", mas sim, de criar propostas em que a complexidade e a diversidade do mundo se evidenciem, sejam parte do problema e de suas possíveis soluções. Os resultados que temos observado a partir do que é desenvolvido na IC do PIXEL, mostram o desenvolvimento de aprendizagens que permitem ao estudante a busca de informações e verificação de fontes, que façam comparações, que defendam seu ponto de vista e que elaborem estratégias e conclusões. A IC do PIXEL é uma proposta de ensino e de aprendizagem que ressignifica o papel do professor, aproximando-o dos estudantes, pois coloca-o na posição de orientador - aquele que tem experiência de pesquisa - e também de pesquisador - aquele que aprende sobre os temas ao longo do trabalho com cada estudante.

\section{Palavras-chave:}

Educação Básica. Iniciação Científica. Interdisciplinaridade.

\begin{abstract}
:
This experience report aims to describe how the curricular component Scientific Initiation (SI) was established and how it is structured as part of PIXEL, which is an educational project for the second half of the final years of elementary school in Colégio de Aplicação (CAp), UFRGS. The work in SI is arranged through a weekly planning of the faculty members, which allowed a series of considerations and practices in this component of
\end{abstract}

$>$ Artigo elaborado pela a equipe de Professores que fazem parte do projeto PIXEL: Vivian Ignes Albertoni, Rosane Nunes Garcia, Felipe Lohmann Arend, Michel Zózimo da Rocha, Luciana Brum, Fabiana Serres, Eduardo Britto Velho de Mattos, Rita de Cássia Cavalcante, Karen Nodari, Maíra Mello, Gabriela Hoffmann Lopes, Clarissa Brunet, Taiane Damaceno, Ivonne Jordam, Ingrid Frank de Ramos, Marcelo Argenta Câmara, Ana Francisca Schneider Grings. A filiação institucional completa encontra-se na última página do artigo. 
the curriculum. Working with SI fosters the development of general skills in both grades in which it is offered ( $8^{\text {th }}$ and $9^{\text {th }}$ years of Elementary School). These include: argumentation, autonomy, authorship, as well as cooperation, collaboration and problem solving. These skills are essential to SI and are the basis for the creation of the evaluation criteria, not only for this curricular component, but for all the other subjects of the PIXEL Project. The SI occurs in four weekly classes and its research projects are developed over a semester. These projects result in structured written productions - in scientific reporting styles for the $8^{\text {th }}$ grade, and in a variety of formats, ranging from reports to manuals for the $9^{\text {th }}$ grade. Both grades are involved in Work Exhibitions, in which students present their research processes using the most diverse resources and give the feedback of their investigation to the community. Therefore, the SI in school is not a class that poses hypothetical problem-situations in the expectation that students will find the 'right' answer. But rather, it is to create propositions in which the complexity and diversity of the world are made evident, are part of the work and that also draw possible solutions for the problems under research. The results that we have observed from what is developed in the SI of Pixel, show the development of learnings that allow the students to search for information and the verification of the sources. Besides this, they become able to make comparisons, to defend their point of view and to develop strategies and conclusions. The SI in PIXEL is a teaching and learning initiative that redefines the role of the teacher, bringing him or her closer to the students, since it places the teacher in the position of the advisor (the one who has research experience) and also of the researcher (the one who learns about the themes throughout the work with each student).

\section{Keywords:}

Basic Education. Scientific Initiation. Interdisciplinarity.

\section{Contextualização do Projeto}

O Projeto PIXEL foi criado em 2010 a partir da necessidade, detectada pelos docentes, de um projeto de ensino coeso que atendesse à segunda metade dos anos finais do Ensino Fundamental, isto é, os $8^{\circ \mathrm{s}}$ e $9^{\text {os }}$ anos do Colégio de Aplicação (CAp) da UFRGS. O objetivo principal do Projeto era o de construir metodologias de ensino voltadas para essa etapa de escolarização, estabelecendo uma identidade do fazer pedagógico que considerasse a continuidade do trabalho realizado com os alunos nos projetos de ensino de etapas anteriores do CAp, a saber, o Projeto Unialfas (do $1^{\circ}$ ao $5^{\circ}$ anos) e o Projeto Amora $\left(6^{\circ}\right.$ e $7^{\circ}$ anos) e que preparasse os estudantes para seu ingresso no Ensino Médio na escola.

A partir dessa perspectiva, buscou-se a formação de um perfil específico de estudante através do oferecimento do componente curricular Iniciação Científica (IC), bem como de práticas multidisciplinares, interdisciplinares e transdisciplinares. Além disso, o Projeto, desde sua concepção, pretendeu ampliar os conhecimentos específicos de cada componente curricular, explorando pontos comuns entre eles e aproximando a vivência escolar das experiências cotidianas, o que auxiliaria os aprendizes na construção de um conhecimento integrado.

Uma vez que o Projeto se consolidou e se concretizou através do trabalho contínuo de um coletivo de professores que vêm nele atuando desde 2011, a partir do projeto original de 2010, é possível dizer que o processo de estudo e de construção de uma base teóricometodológica está sempre em andamento. Assim, este relato de experiência apresenta o componente curricular IC no Projeto PIXEL e o modo como está constituído atualmente, 
descrevendo o formato a que se chegou a partir das práticas e dos estudos teóricos realizados pela Equipe de Professores ao longo do ano de 2017.

\section{Competências previstas no Projeto}

O trabalho com IC no Projeto PIXEL oportuniza o desenvolvimento de competências gerais em ambos os anos de seu desenvolvimento. São elas: a argumentação, a autonomia, a autoria, a cooperação e a colaboração e a resolução de problemas. Essas competências são essenciais à IC e servem como referência para criar os critérios de avaliação não somente desse componente curricular, mas de todos os demais componentes do Projeto de Ensino PIXEL.

Figura 1 - Mapa conceitual que indica as relações entre as competências a serem desenvolvidas pelos estudantes do PIXEL na segunda etapa dos anos finais do Ensino Fundamental

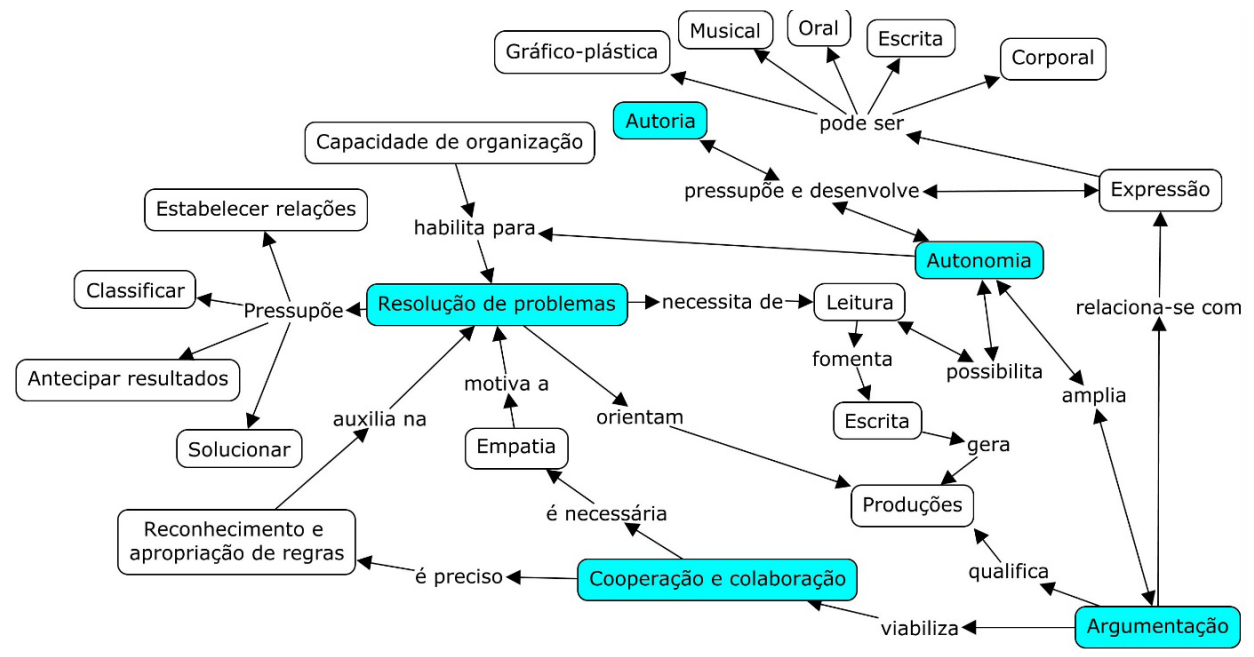

Fonte: Elaborado pelos autores.

A competência da argumentação evidencia-se durante o processo de pesquisa, quando os estudantes são levados a explicar as razões pelas quais escolhem seus temas/ assuntos, as metodologias a serem utilizadas e a forma preferencial de apresentarem suas conclusões. Dá-se grande importância para a qualidade dos argumentos, a fim de que os estudantes reflitam posicionamento crítico, seleção correta de fontes, bem como informações e clareza na exposição das opiniões.

O desenvolvimento da autonomia está presente ao longo de todo o processo de pesquisa e se sobressai ao menos em três momentos distintos, compreendidos pela escolha do tema e do assunto, pela busca por informações e dados e sua estruturação em uma produção (usualmente) escrita coerente, e pelo desenvolvimento de uma forma prática de apresentação de seus resultados na Mostra de Trabalhos de IC. Os três momentos exigem que os estudantes desenvolvam estratégias de organização de seus materiais, seja através de textos escritos, seja pela forma de armazenar os dados coletados, seja no discernimento das fontes de pesquisa adequadas e confiáveis.

A autoria concretiza-se por meio dos textos produzidos pelos estudantes, que devem refletir sobre seus argumentos e opiniões. A orientação dos professores respeita as curiosidades dos estudantes e apresenta caminhos, convidando-os a escolherem aqueles que melhor os auxiliem e melhor reflitam a expressão de suas descobertas e conclusões. Para que esse processo seja estimulante, a Equipe de Professores acredita que o estudante 
deva se sentir confortável e confiante para escolher pesquisar algo que lhe seja de real e pessoal interesse.

A cooperação e a colaboração se dão quando o estudante, ao compreender os fundamentos da escolha do nome do Projeto PIXEL - um pequeno ponto luminoso que só forma uma imagem a partir de sua multiplicação e união, naturaliza o compartilhamento construtivo de informações e dados como parte necessária de seu processo de pesquisa e do aprendizado dos grupos em que atua. O diálogo e os debates no coletivo auxiliam no desenvolvimento da empatia, no reconhecimento e na valorização da alteridade e das experiências do outro, assim como permitem aos professores trabalharem com questões bastante presentes na faixa etária, que se caracteriza por mudanças físicas e emocionais que frequentemente têm impacto nas relações interpessoais e na autoestima dos alunos.

A resolução de problemas, por fim, é competência também presente no Projeto, que representa um dos grandes desafios da educação contemporânea. Ela consiste no desenvolvimento de práticas pedagógicas que não sejam centradas nos conteúdos de cada componente curricular, e sim na utilização desses conhecimentos em situações do dia a dia, como ferramentas para que se lide com situações-problema. Dessa forma, a IC coloca-se como espaço privilegiado para que essas situações-problema sejam trabalhadas no ambiente escolar.

\section{Características da Iniciação Científica no Projeto}

A fim de auxiliar cada aluno na escolha de seu primeiro assunto de pesquisa do ano, a Equipe de Professores, por meio de planejamento conjunto, prepara atividades que podem ser aulas integradas, saídas a campo, palestras com convidados, jogos ou gincanas. As atividades podem ser multi- ou interdisciplinares, agrupando turmas do mesmo ano, ou entre turmas de anos diferentes, com o objetivo de mobilizar a curiosidade dos estudantes para que formulem seus problemas de pesquisa. Depois dessas vivências e de debates realizados nas turmas completas, os estudantes são divididos em grupos menores de investigação, definidos conforme a Língua Estrangeira que o aluno optou estudar, o que resulta em quatro grupos diferentes por ano escolar, com uma média de quinze estudantes por grupo ${ }^{1}$.

Cada um dos grupos de IC do ano conta com uma média de três professores-orientadores provenientes de diferentes Áreas do Conhecimento. Eles devem procurar construir: a. um ambiente que acolha a curiosidade e os conhecimentos prévios dos estudantes em seus caminhos de pesquisa individuais, contando com sua própria experiência de professor pesquisador; b. um percurso coletivo de colaboração, em que todos têm acesso a todos os trabalhos de seu grupo e podem interferir positivamente no trabalho uns dos outros, dando sugestões e trazendo referências, bem como montando coletivamente apresentações, como as da Mostra de Trabalhos.

A IC no PIXEL ocorre em quatro períodos semanais e seus projetos são desenvolvidos ao longo de um semestre. Eles culminam em produções escritas estruturadas - em formatos de reportagem científica para os $8^{\circ \text { s }}$ anos, e com formatos diversos, que incluem desde relatórios até manuais para os $9^{\circ}$. Ambos os anos envolvem-se em Mostras de Trabalhos, nas quais os estudantes apresentam seus processos de pesquisa utilizando-

$1>$ As turmas da IC no PIXEL são mantidas com a mesma configuração das turmas de Línguas Estrangeiras, com o objetivo de favorecer a construção de uma identidade de grupo, reduzindo-se assim os momentos de separação dos estudantes entre si ao longo de cada turno de aulas. se dos mais diversos recursos, tais como vídeos curtos, cenas, maquetes, intervenções, instalações, exposições e revistas. As Mostras são os momentos em que acontecem a devolutiva dos processos de investigação para a comunidade, e sua preparação inclui reflexões sobre a dinâmica de apresentação dos dados, sobre a possibilidade da utilização de recursos lúdicos e sobre a necessidade de adequação da fala aos interlocutores. Alunos 
e professores da escola comparecem e prestigiam as apresentações, que são abertas a toda a comunidade do CAp; também são convidadas outras escolas, e é enviado um convite especial às famílias dos estudantes.

A partir do ano de 2014, a Equipe de Professores, após reflexões a respeito da importância de se desenvolverem aprendizagens acerca do uso de diferentes mídias, passou a requisitar aos alunos do $9^{\circ}$ ano a produção de um vídeo curto, ao invés da participação na Mostra de fim de ano. Desde então, esses vídeos podem ser desenvolvidos por grupos de alunos de variadas quantidades de membros, desde que dentro de cada turma de IC, e devem expressar de alguma forma o processo e as conclusões das pesquisas realizadas no primeiro semestre. Os vídeos são apresentados para diversos setores da comunidade escolar através de um Festival, que inclui a apreciação por um corpo de jurados externo à Equipe de Professores e por júri popular, culminando em uma premiação para diferentes categorias de produção.

\section{Eixos integradores: o trabalho com conceitos-chave}

As aulas de IC no PIXEL, a cada início de ano letivo, têm se desenvolvido principalmente a partir de Atividades Desencadeadoras, também chamadas de Disparadoras, cujo objetivo principal é apresentar aos estudantes os conceitos-chave de sua etapa de ensino com base em uma perspectiva interdisciplinar. Os conceitos-chave de identidade, para o $8^{\circ}$ ano, e de espaço-tempo para o $9^{\circ}$ ano são, portanto, abordados em diferentes atividades pelos professores das diversas Áreas do Conhecimento, com o objetivo de despertar curiosidades e favorecer a construção de relações entre as suas pesquisas e os conceitos-chave.

Entre os anos de 2011 e 2014, as Atividades Desencadeadoras da IC ocorreram através de aulas integradas planejadas pela Equipe de Professores, levando em conta a necessidade de se explorarem determinados assuntos ou de se desenvolverem habilidades específicas. Uma vez que a Equipe tem a convicção de que a integração entre componentes curriculares é imprescindível para uma educação de qualidade, adota-se essa perspectiva multi-, inter- e transdisciplinar, e se pretende que as aulas sejam planejadas de forma conjunta com a maior frequência possível.

Segundo Morin,

[...] interdisciplinaridade pode significar também troca e cooperação, o que faz com que a interdisciplinaridade possa vir a ser alguma coisa orgânica. A multidisciplinaridade constitui uma associação de disciplinas, por conta de um projeto ou de um objeto que lhes sejam comuns; as disciplinas ora são convocadas como técnicos especializados para resolver tal ou qual problema; ora, ao contrário, estão em completa interação para conceber esse objeto e esse projeto, como no exemplo da hominização. No que concerne à transdisciplinaridade, trata-se frequentemente de esquemas cognitivos que podem atravessar as disciplinas, às vezes com tal virulência, que as deixam em transe. De fato, são os complexos de inter-multi-trans-disciplinaridade que realizaram e desempenharam um fecundo papel na história das ciências; é preciso conservar as noções chave que estão implicadas nisso, ou seja, cooperação; melhor, objeto comum; e, melhor ainda, projeto comum (MORIN, 2015, p. 115). 
No entanto, também se entende que o estabelecimento de relações entre conceitos de diferentes componentes curriculares pode e deve dar-se a partir do aprofundamento e da abordagem realizados pelos especialistas nas diferentes Áreas de Conhecimento. De acordo com Japiassu,

[...] o papel específico da atividade interdisciplinar consiste, primordialmente, em lançar uma ponte para religar as fronteiras que haviam sido estabelecidas anteriormente entre as disciplinas com o objetivo preciso de assegurar a cada uma, seu caráter propriamente positivo, segundo modos particulares e com resultados específicos (JAPIASSU, 1976, p. 75).

Considera-se, portanto, de extrema importância a existência dos conhecimentos disciplinares estabelecidos em cada componente curricular para que seja possível a estruturação de ações multi-, inter- e transdisciplinares no PIXEL. Por isso, os professores que inicialmente conceberam o Projeto de Ensino organizaram o currículo de forma horizontalmente integrada, com conteúdos que dialogavam em cada um dos dois anos dessa etapa de ensino.

Em 2015, a Equipe de Professores reorganizou oficialmente o currículo do Projeto em torno da identificação de conceitos-chave que apareciam sistematicamente nos planos de ensino de todos os componentes curriculares. Dessa forma, o fluxo dos conceitos entre um componente curricular e outro ficaria facilitado e permitiria aos estudantes construírem relações de forma mais autônoma, adequada e qualificada. Esses conceitos-chave que emergiram dos planos de ensino dos diferentes componentes curriculares trouxeram uma transversalidade ao currículo, facilitando a construção por parte da Equipe de Professores com objetivos de aprendizagem comuns a todas as Áreas de Conhecimento.

Agregaram-se ao conceito-chave identidade estabelecido para os $8^{\text {os }}$ anos outros conceitos relacionados, tais como região, espaço, tradição, estética, aparência, padrão de beleza, estereótipo, personalidade, hábitos e cultura. Já ao conceito-chave dos $9^{\text {os }}$ anos de espaço-tempo, somaram-se outros conceitos também relacionados, como universo, fronteira, movimento e corpo. A seleção desses conceitos ocorreu a partir de reuniões pedagógicas nas quais, através da construção conjunta de mapas conceituais, foi possível evidenciar interseções e diálogos existentes entre as diferentes Áreas de Conhecimento. Dessa forma, a Equipe de Professores pôde estruturar um planejamento transversal e anual das Áreas, assim como também um planejamento transversal e anual entre os diferentes componentes curriculares do Projeto. A cada ano, a listagem de conceitos inter-relacionados é reavaliada pela Equipe, levando-se em conta possíveis alterações curriculares, bem como o desejo e o interesse demonstrados por estudantes e/ou docentes de se abordarem assuntos diferentes dos planejados anteriormente.

Os conceitos e eixos cumprem um papel importantíssimo na IC, como foi detalhado neste relato (Item 3); quanto às Atividades Desencadeadoras, já existe um conjunto bem consolidado delas. Mesmo que possam apresentar variações de ano para ano, elas se organizam em geral em torno das seguintes propostas: 


\section{Quadro sobre os 8 e 9 anos}

\section{Para as turmas de 8 ano}

a. assistência a curtas-metragens de animação cuja temática é a identidade, seja no que se refere à permanência e à transitoriedade de rotinas e tradições, ao espírito de grupo e de coletividade versus bullying, seja na reflexão sobre o respeito às diferenças e sobre comportamentos individuais diante de grupos sociais;

b. reconhecimento e análise de tipos de conhecimento, suas características, métodos e acréscimos à compreensão de mundo. Os quatro tipos selecionados são: o senso comum (exemplificado por ditados populares e afirmações passadas de geração em geração, sem exigência de conhecimentos aprofundados ou comprovação, pois apoiam-se na experiência pessoal), o conhecimento mitológico ou religioso (trata-se de crenças inquestionáveis que envolvem fé no sobrenatural), o conhecimento filosófico (designa estudos mais especulativos que se dão a partir da interpretação apoiada em argumentação sólida, como a leitura de obras de Arte e reflexões sobre questões ligadas ao comportamento humano) e o conhecimento científico (caracterizado pela coleta, organização e análise de dados e similar ao Método Científico clássico). Após o estudo desses quatro tipos de conhecimento, os alunos procedem a uma atividade em que devem, a partir de exemplos e coletivamente, detectar o tipo de conhecimento empregado.

\section{Para as turmas de 9o ano}

a. assistência a filmes (inteiros ou a trechos selecionados), cenas de séries, videoclipes ou documentários, com a temática em torno do conceito de espaço-tempo para posteriores reflexões com as turmas;

b. preparação de uma pequena mostra de trabalhos variados (cartazes, vídeos, etc.) em que os próprios alunos do $9^{\circ}$ ano explicam aos do $8^{\circ}$ ano, a partir de suas experiências prévias, o que é Iniciação Científica e como ela se dá no componente curricular do Projeto PIXEL.

\section{Para ambos os anos}

a. leitura de textos (como reportagens, notícias, resumos, artigos completos), cuja discussão, através de abordagem transdisciplinar, leve ao debate dos conceitos-chave previamente estabelecidos;

b. oficinas com professores ou profissionais externos à escola, especialistas em suas Áreas de Conhecimento, sobre os conceitos-chave do ano em questão.

Fonte: Elaborado pelos autores

\section{As contribuições da cartografia poética em projetos de pesquisa}

Jean Lancri, no contexto de uma pesquisa em Artes Visuais, a qual se encontra entre o fazer e o pensar como criação de uma metodologia, tenta responder a seguinte pergunta:

Por onde começar? Muito simplesmente pelo meio. É no meio que convém fazer a sua entrada ao assunto. De onde partir? Do meio de uma prática, de uma vida, de um saber de uma ignorância. Do meio desta ignorância que é bom buscar o âmago do que se crê saber melhor. O conselho não é novo. Deleuze e Guattari, recentemente, e antes Valéry, antes deles, prodigalizavam outros tantos (LANCRI, 2002, p. 18).

Ao transpor tais colocações para o campo de inserção do Projeto PIXEL e, ao considerar a faixa etária dos alunos envolvidos, podemos refletir sobre os assuntos ou temas escolhidos por eles para serem investigados. Em sua maioria, os alunos, ao escolherem seus temas iniciais de pesquisa na IC, dão prioridade a assuntos muito parecidos com aqueles que já foram investigados por eles em anos anteriores. Aparentemente, isso parece ser uma espécie de problema que os impediria de averiguar novos assuntos, pois circundariam sempre a mesma esfera de interesse e, consequentemente, ignorariam novos 
campos a serem experienciados. Do mesmo modo, essas escolhas parecem ser justificadas por uma espécie de acomodação, refratária a possíveis dificuldades de começar um novo projeto de pesquisa e escolher um assunto desconhecido, ainda não estudado. No entanto, levando em consideração as observações de Lancri sobre como iniciar uma pesquisa, cabe perguntar: o meio de uma pesquisa anterior poderia ser o ponto de partida de um novo projeto de IC?

Ao iniciar o ano letivo, os assuntos relacionados aos campos de interesse dos alunos em anos anteriores ainda reverberam nos principais temas levantados nos primeiros encontros. Temas que parecem povoar o imaginário infantil, a cultura de massa e o senso comum despontam como os primeiros assuntos escolhidos pelos estudantes para serem investigados. Nessa lógica, cabe outra interrogação: de que forma um assunto já pesquisado poderia ser investigado em um novo projeto de pesquisa? Diante dessa questão, surgem novas perguntas que não se esgotam facilmente diante da insistência dos alunos em manter o interesse em temas inicialmente propostos por eles: as dúvidas da pesquisa anterior foram todas respondidas? Por que pesquisar esse mesmo assunto? Há uma forma de olhar para o mesmo tema por um outro viés que complemente as pesquisas anteriores, gerando questionamentos que impulsionem novos projetos de IC?

De modo distinto, igualmente podem ser problematizadas as temáticas novas trazidas pelos alunos que parecem se distanciar radicalmente dos campos de interesse trabalhados em projetos anteriores de IC. Há, aqui, outro questionamento que merece atenção, pois relaciona-se com a inconstância de interesses relativa à faixa etária dos alunos. Pensando ainda a partir da ideia de "meio como ponto zero", de Lancri, que considera que uma pesquisa nunca inicia sem se ancorar em outras investigações sobre o mesmo assunto: "Há produção, invenção, descoberta [portanto avanço de conhecimento] se faço existir o que antes não existia, mas que sem mim teria podido existir" (LANCRI, 2002, p. 33). Nesse sentido, o meio do caminho não seria a pesquisa anterior do aluno, mas sim a(s) possível(is) pesquisa(s) de outro(s) investigador(es). Assim, considerando essa ideia, é importante que, nas atividades de IC realizadas pelos estudantes no Projeto PIXEL, sejam levantadas inicialmente o maior número de pesquisas que já investigaram o assunto por ele escolhido, para que eles verifiquem se a sua questão já não foi respondida por alguém em algum lugar.

Ao considerar que todo projeto de IC é um veículo investigativo que transita entre distintos campos de saberes e práticas, que desenham múltiplos trajetos ao longo de seu processo, é possível trazer elementos para reflexão a partir do conceito de cartografia poética. Tal expressão refere-se ao registro que documenta e mapeia todos os caminhos percorridos por uma pesquisa. Um mapa pode ser entendido como um desenho que demarca um lugar ou um território, determinando a porção de espaço num dado momento. Sua função pode ser a de facilitar nossa orientação nesse espaço, revelando uma área, de um determinado ponto de vista, em uma escala muito menor do que a real. Já a cartografia, é a ciência que concebe, produz, utiliza e estuda os mapas. A cartografia poética, em projetos de pesquisa, pode ser usada muito mais para inventar mundos do que para mapear ou reconhecer aqueles que já existem. Conforme Deleuze e Guattari:

O mapa é aberto, é conectável em todas as suas dimensões, desmontável, reversível, suscetível de receber modificações constantemente. Ele pode ser rasgado, revertido, adaptar-se a montagens de qualquer natureza, ser preparado por um indivíduo, um grupo ou uma formação social. Pode-se desenhá-lo numa parede, concebê-lo como obra de arte, construí-lo como uma ação política ou como uma meditação (1996, p. 22). 
Como um elemento de registro de pesquisas, a cartografia poética acompanha os processos, as trajetórias, os desvios, os caminhos trilhados e aqueles que foram abandonados durante o desenvolvimento das investigações dos alunos. Ela não tem regras de elaboração, estando aberta a possíveis e infinitas interpretações de como fazer. Entretanto, ela concentra-se nas pistas e nos rastros do processo que pode levar à construção de um produto que registra as aprendizagens dos estudantes. Esse produto pode ser um grande desenho, uma série de anotações, pensamentos, frases, um mural com muitas imagens, um vídeo, um livro, uma revista, ou ser o conjunto de todos esses e outros elementos.

\section{Premissas da Iniciação Científica no PIXEL}

$\mathrm{Na}$ etapa da escolarização aqui em questão, a Equipe de Professores do Projeto PIXEL concebe IC como uma preparação para a pesquisa e para o pensamento interrogativo, com vistas à produção do conhecimento através de diversos métodos e metodologias. Nesse sentido, espera-se que os estudantes formulem dúvidas e problemas a partir de seus interesses genuínos, tendo como objetivo o desenvolvimento do pensamento crítico. A proposta de IC desenvolvida no Projeto está em consonância com as experiências curriculares inovadoras do CAp e promove uma continuidade dessas experiências ao colocar o estudante no centro do processo de aprendizagem, buscando subsídios teóricos que expliquem como os jovens aprendem para, assim, desenvolver práticas pedagógicas adequadas.

Outro ponto essencial para a estruturação da IC no Projeto PIXEL é o papel de mediador desempenhado pelo professor. É importante que ele seja efetivo partícipe dos projetos que orienta, contribuindo para a ampliação dos horizontes de pesquisa do estudante, em termos de apontamento tanto de fontes de consulta quanto de possibilidades metodológicas. Nesse sentido, a presença de especialistas de diferentes Áreas do Conhecimento é fundamental para que referências e práticas diversas possam ser colocadas à disposição dos alunos.

A Equipe destaca alguns elementos que fundamentam seu entendimento sobre IC: a. os estudantes devem ter uma postura ativa na construção de sua própria aprendizagem; b. as atividades pedagógicas devem ser permeadas por situações complexas, desafiadoras e inéditas para o aprendiz, de modo que ele precise se mobilizar cognitivamente para a construção de novos caminhos; $c$. a escola deve oferecer fontes variadas de informação e possibilitar aos estudantes acessos criativos e inovadores ao conhecimento, assim como possibilitar utilizações criativas e inovadoras desse conhecimento; $d$. as propostas de trabalho não devem ser lineares, e sim priorizar a investigação do estudante e o trabalho em rede, dialogando ou estando em contato com outras pesquisas em andamento, com os demais componentes curriculares ou com ações que estejam sendo desenvolvidas na comunidade escolar.

A IC é uma das formas de abrir espaços e tempos no currículo do Projeto para a construção de conhecimentos de forma mais integrada. Esse componente curricular é pensado coletivamente pela Equipe de Professores e estabelece ligações entre os diferentes saberes, favorecendo o desenvolvimento de aprendizagens que não se centralizam no professor. Promovem-se espaços para acolher as indagações e curiosidades dos estudantes, que irão se articular de forma integrada ao currículo, quebrando a sequencialidade temporal e o isolamento dos saberes que se impõe em um ensino disciplinar.

Outro importante desafio que se apresenta é como trabalhar com a IC nessa etapa de escolaridade $-8^{\circ}$ e $9^{\circ}$ anos - de modo que se diferencie das experiências prévias que os estudantes trazem da etapa imediatamente anterior do CAp, ou seja, do Projeto Amora. O Projeto Amora, que atende os alunos do $6^{\circ}$ e do $7^{\circ}$ anos, também trabalha com uma 
concepção de ensinar e aprender a partir de práticas investigativas através de Projetos de Aprendizagem, em consonância com os aspectos próprios da faixa etária que se apresentam nesse período. Ao PIXEL cabe, portanto, continuar esse trabalho ao mesmo tempo em que o amplia e aprofunda.

\section{Considerações finais}

A partir dos pressupostos teóricos apresentados em relação à IC, torna-se possível trazer elementos diferentes ao que já foi vivenciado pelos estudantes em anos anteriores do Ensino Fundamental. Diferentes formas de registros das pesquisas são vivenciadas para relatar as suas aprendizagens, quer seja na Mostra de Trabalhos, momento em que os estudantes são desafiados a apresentarem de forma original seu processo de investigação, quer seja no desenvolvimento de vídeos, no $9^{\circ}$ ano, quando a pesquisa deve ser transposta para uma mídia audiovisual.

A escola, dessa maneira, abre-se para a vida e para o contexto sociocultural do estudante e, por extensão, para toda a comunidade. Não se trata, portanto, de uma aula que propõe situações-problema hipotéticas na expectativa de que os estudantes encontrem a resposta correta, mas sim de criar propostas em que a complexidade e a diversidade do mundo se evidenciem, sejam parte do problema e de suas possíveis soluções.

A desacomodação, conceito caro a Piaget, é radicalizada na perspectiva de Morin, tornando-se não um momento essencial ao aprendizado, e sim o movimento permanente para a compreensão do mundo.

Um sistema fechado, como uma pedra, uma mesa, está em estado de equilíbrio, ou seja, as trocas de matéria/energia com o exterior são nulas. Por outro lado, a constância da chama de uma vela e a constância do meio interno de uma célula, ou de um organismo, não estão absolutamente ligadas a tal equilíbrio; ao contrário, há desequilíbrio no fluxo energético que os alimenta, e, sem este fluxo, haveria desordem organizacional levando rapidamente ao definhamento. (MORIN, 2015, p. 21)

Ao longo dos anos de desenvolvimento do Projeto de Ensino PIXEL, o grupo de professores tem vivenciado diferentes experiências que possibilitam um fazer pedagógico que foge dos modelos tradicionais de ensinar e aprender, oportunizando novos desafios para professores e alunos. O trabalho de planejamento semanal conjunto entre os professores é peça fundamental para o desenvolvimento da IC no PIXEL. Além disso, o estabelecimento de competências comuns para esta etapa de ensino abre possibilidades não só para aprendizagens que são importantes em relação à assimilação de conceitos, mas também para aprendizagens mais amplas, que acompanharão os estudantes em diferentes contextos, tanto no ambiente escolar quanto nas atividades da vida não acadêmica.

Acompanhando as pesquisas produzidas pelos alunos, em sua passagem pela IC no Projeto PIXEL, percebemos diferentes níveis de desenvolvimento dos trabalhos. Os resultados apresentados nem sempre atingem o esperado, variando de acordo com o comprometimento, envolvimento e as condições cognitivas de cada estudante. Mas, analisando o processo, notamos que a postura dos estudantes, em relação à forma como encaram as atividades de IC, assim como também as suas aprendizagens, à medida que avançam no período letivo, vão se modificando, aprofundando e agregando os elementos e as metodologias que são trabalhados na disciplina.

O trabalho com a IC traz uma proposta de ensino e de aprendizagem que ressignifica o papel do professor, aproximando-o dos estudantes, pois coloca-o na posição de orientador - aquele que tem experiência de pesquisa - e também de pesquisador - aquele 
que aprende sobre os temas ao longo do trabalho com cada estudante. Cabe destacar que isso é possível porque cada turma de IC conta, por grupo, com uma média de quinze estudantes e de três professores de Áreas do Conhecimento diferentes.

O resultado desse processo de acompanhamento próximo e de troca de saberes leva a um notável desenvolvimento dos estudantes, no que diz respeito às habilidades que o Projeto PIXEL destaca como essenciais para a faixa etária (argumentação, autonomia, autoria, cooperação e colaboração e resolução de problemas). As experiências de IC aqui relatadas permitem ao aluno que busque informações e verifique fontes, faça comparações, defenda seu ponto de vista e elabore estratégias e conclusões.

Acredita-se, então, que é com base no que foi anteriormente exposto que se dá o fortalecimento dos vínculos entre a comunidade escolar e que se contribui efetivamente para a formação dos estudantes, que têm a oportunidade de desenvolverem, a partir de seus diferentes interesses e identidades, a postura de aprendizes frente aos desafios da vida.

\section{Referências}

DELEUZE, Gilles; GUATTARI, Félix. Mil platôs. Rio de Janeiro: Editora 34, v.1, 1996.

JAPIASSU, Hilton. Interdisciplinaridade e patologia do saber. Rio de Janeiro: Imago, 1976.

LANCRI, Jean. Colóquio sobre a metodologia da pesquisa em artes plásticas na universidade. In: BRITES, Blanca; TESSLER, Elida (orgs.). O meio como ponto zero: metodologia da pesquisa em artes plásticas. Porto Alegre: Editora da UFRGS, 2002. p.15-34.

MORIN, Edgar. Introdução ao pensamento complexo. Porto Alegre: Sulina, 2015.

\section{Filiação Institucional dos autores}

Listamos aqui todos os professores do projeto PIXEL quando este artigo foi escrito e a respectiva filiação institucional. Vivian Ignes Albertoni: Doutora em Literatura Brasileira pela UFRGS. Professora de Literatura e Língua Portuguesa no Colégio de Aplicação da UFRGS - vivianignes@ gmail.com; Rosane Nunes Garcia: Professora de Ciências Biológicas no Colégio de Aplicação da UFGRS - rosanebio2007@gmail.com; Felipe Lohmann Arend: Professor de Ciências Biológicas no Colégio de Aplicação da UFGRS - felipelohmannarend@gmail.com; Michel Zózimo da Rocha: Professor de Artes Visuais no Colégio de Aplicação da UFRGS - ideiasquenaoderamcerto@gmail.com; Luciana Brum: Professora de Artes Visuais no Colégio de Aplicação da UFRGS - lubrum1@gmail. com; Fabiana Serres: Professora de Matemática no Colégio de Aplicação da UFRGS - fabianaserres@ gmail.com; Eduardo Britto Velho de Mattos: Professor de Matemática no Colégio de Aplicação da UFRGS - dudubritto@yahoo.com.br; Rita de Cássia Cavalcante: Professora de Literatura e Língua Portuguesa no Colégio de Aplicação da UFRGS - ritaccav@gmail.com; Karen Nodari: Professora aposentada. Titular do Departamento de Humanidades do Colégio de Aplicação e Orientadora Educacional da Equipe Pixel até 2017 - karen.nodari@terra.com.br; Maíra Mello: Professora de Língua Inglesa no Colégio de Aplicação da UFRGS - maira.mello@terra.com.br; Gabriela Hoffmann Lopes: Professora de Língua Alemã no Colégio de Aplicação da UFRGS - gabrielahlopes@gmail.com; Clarissa Brunet: Professora de Língua Francesa no Colégio de Aplicação da UFRGS - cbrunetcap@ gmail.com; Taiane Damaceno: Professora de Língua Francesa. Substituta no Colégio de Aplicação da UFRGS entre 2017 e 2019 - taianedamaceno@gmail.com; Ivonne Jordam: Professora de Língua Espanhola no Colégio de Aplicação da UFRGS - ivonnejordam@gmail.com; Ingrid Frank de Ramos: Professora de Língua Inglesa no Colégio de Aplicação da UFRGS - ingridfrank123@gmail.com; Marcelo Argenta Câmara: Professor no Departamento de Geografia da UFRGS - argentacamara@ hotmail.com; Ana Francisca Schneider Grings: Professora de Música no Colégio de Aplicação da UFRGS - anagringsufrgs@gmail.com. 
